\title{
Regulatory Effects of Propofol on High-Dose Remifentanil-Induced Hyperalgesia
}

\author{
Xiaohu SU ${ }^{1}$, Wei ZHU ${ }^{2}$, Yufeng TIAN ${ }^{1}$, Lei TAN ${ }^{1}$, Hao WU ${ }^{1}$, Lei WU ${ }^{1}$ \\ ${ }^{1}$ Department of Anesthesiology, Suqian First Hospital, Suqian, Jiangsu Province, P. R. China, \\ ${ }^{2}$ Department of Anesthesiology, Jiangsu Province Hospital, Nanjing, Jiangsu Province, P. R. China
}

Received February 1, 2019

Accepted November 20, 2019

Epub Ahead of Print December 19, 2019

\section{Summary}

We aimed to evaluate the regulatory effects of propofol on highdose remifentanil-induced hyperalgesia. A total of 180 patients receiving laparoscopic cholecystectomy were randomly divided into sevoflurane + high-dose remifentanil (SH) group, sevoflurane + low-dose remifentanil (SL) group and propofol + high-dose remifentanil group $(\mathrm{PH})$ group $(n=60)$. After intravenous administration of midazolam, SH and SL groups were induced with sevoflurane and remifentanil, and $\mathrm{PH}$ group was induced with propofol and remifentanil. During anesthesia maintenance, SH and SL groups were given $0.3 \mu \mathrm{g} / \mathrm{kg} / \mathrm{min}$ and $0.1 \mu \mathrm{g} / \mathrm{kg} / \mathrm{min}$ sevoflurane and remifentanil respectively, and $\mathrm{PH}$ group was given $0.3 \mu \mathrm{g} / \mathrm{kg} / \mathrm{min}$ propofol and remifentanil. The three groups had significantly different awakening time, extubation time and total dose of remifentanil $(P<0.001)$. Compared with SL group, periumbilical mechanical pain thresholds $6 \mathrm{~h}$ and $24 \mathrm{~h}$ after surgery significantly decreased in $\mathrm{SH}$ group $(\mathrm{P}<0.05)$, and the visual analog scale (VAS) scores significantly increased $30 \mathrm{~min}, 2 \mathrm{~h}$ and $6 \mathrm{~h}$ after surgery $(P<0.05)$. Compared with $\mathrm{SH}$ group, periumbilical mechanical thresholds $6 \mathrm{~h}$ and $24 \mathrm{~h}$ after surgery were significantly higher in $\mathrm{PH}$ group $(\mathrm{P}<0.05)$, and VAS scores $30 \mathrm{~min}, 2 \mathrm{~h}$ and $6 \mathrm{~h}$ after surgery were significantly lower $(\mathrm{P}<0.05)$. $\mathrm{PH}$ group first used patient-controlled intravenous analgesia pump significantly later than $\mathrm{SL}$ group did $(\mathrm{P}<0.05)$. The total consumptions of sufentanil in $\mathrm{PH}$ and $\mathrm{SL}$ groups were significantly lower than that of $\mathrm{SH}$ group $(\mathrm{P}<0.05)$. The incidence rates of bradycardia and postoperative chill in $\mathrm{PH}$ and $\mathrm{SH}$ groups were significantly higher than those of $S L$ group $(P<0.05)$. Anesthesia by infusion of highdose remifentanil plus sevoflurane caused postoperative hyperalgesia which was relieved through intravenous anesthesia with propofol.

\section{Key words}

Remifentanil • Hyperalgesia • Propofol

\section{Corresponding author}

W. Zhu, Department of Anesthesiology, Jiangsu Province Hospital, Nanjing 210029, Jiangsu Province, P. R. China. E-mail: zhuweijph@yahoo.com, Y. Tian, Department of Anesthesiology, Suqian First Hospital, Suqian 223800, Jiangsu Province, P. R. China. E-mail: tianyufengsfh@foxmail.com

\section{Introduction}

Opioids, as the most commonly used analgesic drugs in clinical practice, are widely used for general anesthesia, postoperative analgesia and chronic pain alleviation. However, opioids may cause acute tolerance and hyperalgesia. Acute opioid tolerance (AOT) refers to reduction in the therapeutic effects, requiring higher doses to maintain the analgesic effects. Opioid-induced hyperalgesia $(\mathrm{OIH})$ is a state of pain sensitization, which is manifested as decrease in the threshold of pain, with a shift in the stimulus-pain curve to the left, i.e. stimulus with the same intensity may induce more intense pain. Specifically, patients may become more sensitive to painful stimuli after using opioids for treatment (Bekhit 2010).

As an ultra-short-acting $\mu$ opioid receptor agonist, remifentanil is widely used for general anesthesia due to fast onset, short half-life of elimination, no accumulation, metabolism through non-specific esterases in plasma and tissues, and constant context-sensitive halftime. Basic and clinical studies have verified that

PHYSIOLOGICAL RESEARCH • ISSN 1802-9973 (online) 
AOT and/or OIH occurred after continuous administration of remifentanil (Lee et al. 2011, Ishida et al. 2012). Intraoperative use of high-dose remifentanil may induce postoperative acute pain and hyperalgesia, leading to poor outcomes of early postoperative analgesia (Fletcher and Martinez 2014). The mechanisms of remifentanil-induced AOT and/or OIH remain unclear and may be associated with opioid receptor changes, activation of the NMDA receptor system, reduction of $\gamma$-aminobutyric acid receptor, as well as increased release of opioid peptides, neuropeptides, nociceptin, dynorphin A and cellular inflammatory factors (prostaglandin, interleukin-1, interleukin-6) (Yu et al. 2016). Remifentanil activates inhibitory $\mathrm{G}$ protein by stimulating $\mu$ receptor, exerting analgesic effects through downregulation of intracellular cAMP. Long-term continuous administration of remifentanil can reduce the number of produced receptors and cause opioid tolerance. Then rapid metabolism of remifentanil leads to compensatory up-regulation of cAMP bypass and induces acute tolerance. Besides, remifentanil binds $\mu$ receptor and activates active G protein to induce hyperalgesia. Activation of the NMDA receptor system may be one of the main mechanisms for acute tolerance and/or hyperalgesia (Kaye et al. 2014). Remifentanil can enhance NMDA receptor function by promoting the expressions of NR2B subunits in spinal cord neurons, and facilitate pain signal transduction and central sensitization, finally resulting in hyperalgesia. In addition, remifentanil can agonize $\mu$ receptor, inhibit the glutamate transport system, and increase the glutamate content supplied to NMDA receptors for activation.

Remifentanil is often used in combination with propofol for general anesthesia. Propofol can inhibit the involvement of NMDA glutamate subtype receptors in regulating hyperalgesia (Ahmed et al. 2016). Moreover, propofol can delay and attenuate remifentanil-induced hyperalgesia (Rivosecchi et al. 2014), but related clinical indices are mainly postoperative visual analog scale (VAS) score and postoperative consumption of analgesics. In fact, if the threshold for pain is not directly measured, it is difficult to objectively assess the relationship between use of remifentanil and postoperative hyperalgesia, because one of the characteristics of hyperalgesia is the decrease of pain threshold. Therefore, we herein employed electronic von Frey (EVF) to detect postoperative pain threshold. In combination with postoperative pain score and analgesic consumption, we evaluated the effects of anesthesia using propofol plus remifentanil on remifentanil-induced hyperalgesia.

\section{Subjects and Methods}

\section{Baseline clinical data}

A total of 180 patients (20-60 years old) with ASA grade I-II, who received laparoscopic cholecystectomy, were randomly divided into a sevoflurane + highdose remifentanil group (SH group), a sevoflurane + lowdose remifentanil group (SL group) and a propofol + high-dose remifentanil group (PH group) ( $\mathrm{n}=60)$. Exclusion criteria: Severe cardiopulmonary diseases, hypertension, diabetes, alcohol or drug abuse, history of acute or chronic pain, current administration of analgesics, obesity (body mass index (BMI) $>30 \mathrm{~kg} / \mathrm{m}^{2}$ ), and incorrect use of patient-controlled intravenous analgesia (PCIA) pump. This study has been approved by the ethics committee of our hospital, and written informed consent has been obtained from all patients.

\section{Methods}

The patients fasted and water-deprived before surgery. The venous access was established after entering the operating room, and vital signs were routinely monitored, including blood pressure, oxyhemoglobin saturation, electrocardiogram, anesthetic gas concentration monitoring (Detax-Ohmeda $\mathrm{S} / 5$ monitor, USA) and bispectral index (BIS) measurement (Vista Covidien, USA). After intravenous administration with 2-3 mg of midazolam, SH and SL groups were induced by inhaling sevoflurane, and the circuit was flushed for $3 \mathrm{~min}$ with $71 /$ min of oxygen and $7 \%$ sevoflurane. The patients inhaled sevoflurane by mask for induction, accompanied by assisted ventilation. Two minutes after the start of induction, $4 \mathrm{l} / \mathrm{min}$ of oxygen and $3 \%$ sevoflurane were used. Meanwhile, $2 \mu \mathrm{g} / \mathrm{kg}$ remifentanil was slowly administered and then changed to $0.5 \mu \mathrm{g} / \mathrm{kg} / \mathrm{min}$ for induction. The PH group was injected slowly with $2 \mathrm{mg} / \mathrm{kg}$ propofol and $2 \mu \mathrm{g} / \mathrm{kg}$ remifentanil, and then pumped with $0.5 \mu \mathrm{g} / \mathrm{kg} / \mathrm{min}$ remifentanil for induction. When BIS was lower than $50,0.9 \mathrm{mg} / \mathrm{kg}$ rocuronium was given intravenously, followed by endotracheal intubation. The SH group was anesthetized with $0.3 \mu \mathrm{g} / \mathrm{kg} / \mathrm{min}$ sevoflurane and remifentanil for anesthesia maintenance, the SL group was given $0.1 \mu \mathrm{g} / \mathrm{kg} / \mathrm{min}$ sevoflurane and remifentanil, and the $\mathrm{PH}$ group was given $0.3 \mu \mathrm{g} / \mathrm{kg} / \mathrm{min}$ propofol and remifentanil. The end-tidal carbon dioxide pressure $\left(\mathrm{P}_{\mathrm{ET}} \mathrm{CO}_{2}\right)$ was maintained at $35-45 \mathrm{~mm} \mathrm{Hg}$ 
during surgery. BIS was adjusted within the range of 40-60 by increasing or decreasing the concentration of sevoflurane or propofol. If hypotension (MAP $<60 \mathrm{~mm} \mathrm{Hg}$ ) occurred and was not relieved after $5 \mathrm{~min}$ of rapid infusion, $10 \mathrm{mg}$ ephedrine was intravenously given. When bradycardia $(\mathrm{HR}<45 \mathrm{bpm})$ took place, $0.5 \mathrm{mg}$ atropine was intravenously given. After surgery, neostigmine and atropine were used to antagonize residual muscle relaxants. When patient was awake with good spontaneous breathing, the tracheal tube was extubated after the throat reflex recovered. Thirty minutes before the end of surgery, $5 \mathrm{mg}$ granisetron was administered intravenously. PCIA pump (Apollo Scientific Instruments Co., Ltd., China) was connected immediately after surgery, using $150 \mu \mathrm{g}$ sufentanil and $10 \mathrm{mg}$ granisetron in $150 \mathrm{ml}$ of normal saline. PCIA parameter setting: No background dose, $5 \mathrm{ml}$ for the first dose and $3 \mathrm{ml}$ each time, with lockout time of $15 \mathrm{~min}$. After surgery, patients were transferred to post-anesthesia care unit for further observation.

\section{Monitoring}

Patients were instructed of correctly using VAS and PCIA pump one day before surgery. Mechanical pain threshold was measured at the surgical incision (periumbilical) by an anesthesiologist who was unaware of grouping or intervention methods using EVF (IITC, Life Sciences, USA). Pain threshold measurement: One site $2 \mathrm{~cm}$ above the incision around the umbilicus and two sites $1 \mathrm{~cm}$ away on the left and right were selected for measurement. The device tip was placed vertically on the skin and gradually pressurized until patient felt painful, and then removed. The thresholds were recorded automatically. The average of the above three sites was used as the mechanical pain threshold around the incision. The measurement was performed before and $6 \mathrm{~h}$ and $24 \mathrm{~h}$ after surgery, respectively. The total dose of remifentanil, first time of using PCIA pump, total postoperative sufentanil consumption, awakening time (from stopping using anesthetics to opening eyes by being woken up) and extubation time (from stopping using anesthetics to extubation of tracheal tube) were recorded. The patients were observed for VAS scores $30 \mathrm{~min}, 2 \mathrm{~h}, 6 \mathrm{~h}, 12 \mathrm{~h}$ and $24 \mathrm{~h}$ after surgery, as well as adverse reactions such as intraoperative hypotension, bradycardia, postoperative nausea, vomiting and chill.

\section{Statistical analysis}

All data were analyzed by SPSS 16.0 software. The categorical data were expressed as mean \pm standard deviation or median (interquartile range), and the numerical data were represented as rate. One-way analysis of variance was performed for age, BMI, anesthesia time, surgical time, total consumption of remifentanil, first time of using PCIA pump, awakening time and extubation time. Repeated measures analysis of variance was conducted for mechanical pain threshold, VAS score and total postoperative consumption of sufentanil. Related complications such as intraoperative hypotension, bradycardia, postoperative nausea, vomiting and chill were subjected to the Chi-square or Fisher's exact test. $\mathrm{P}<0.05$ was considered statistically significant.

\section{Results}

\section{Baseline clinical data and related parameters}

The three groups had similar age, body mass index, anesthesia time and surgical time $(\mathrm{P}>0.05)$, but significantly different awakening time, extubation time and total dose of remifentanil $(\mathrm{P}<0.001)$ (Table 1).

Table 1. Baseline clinical data and related parameters $(n=60, X \pm S D)$.

\begin{tabular}{lccccccc}
\hline Group & $\begin{array}{c}\text { Age } \\
\text { (year) }\end{array}$ & $\begin{array}{c}\text { BMI } \\
\mathbf{( k g / \mathbf { m } ^ { 2 } )}\end{array}$ & $\begin{array}{c}\text { Anesthesia } \\
\text { time (min) }\end{array}$ & $\begin{array}{c}\text { Surgical } \\
\text { time (min) }\end{array}$ & $\begin{array}{c}\text { Awakening } \\
\text { time (min) }\end{array}$ & $\begin{array}{c}\text { Extubation } \\
\text { time (min) }\end{array}$ & $\begin{array}{c}\text { Total } \\
\text { remifentanil dose } \\
(\boldsymbol{\mu g})\end{array}$ \\
\hline$S L$ & $45.5 \pm 6.9$ & $24.3 \pm 3.2$ & $88.3 \pm 8.7$ & $59.7 \pm 3.1$ & $9.8 \pm 2.5$ & $10.7 \pm 2.3$ & $632.8 \pm 29.8$ \\
$S H$ & $45.8 \pm 6.7$ & $24.1 \pm 3.0$ & $88.1 \pm 8.8$ & $59.6 \pm 3.0$ & $8.7 \pm 2.7$ & $9.3 \pm 2.2$ & $1693.9 \pm 33.89$ \\
$P H$ & $45.7 \pm 6.8$ & $24.2 \pm 3.1$ & $87.9 \pm 8.6$ & $60.2 \pm 3.3$ & $7.3 \pm 2.6$ & $7.8 \pm 2.3$ & $1768.9 \pm 34.6$ \\
$P$ & 0.847 & 0.704 & 0.799 & 0.809 & $<0.001$ & $<0.001$ & $<0.001$ \\
\hline
\end{tabular}

BMI: Body mass index; PH: propofol + high-dose remifentanil group; SH: sevoflurane + high-dose remifentanil; SL: sevoflurane + lowdose remifentanil. 
Postoperative periumbilical mechanical pain thresholds

Compared with SL group, the periumbilical mechanical pain thresholds $6 \mathrm{~h}$ and $24 \mathrm{~h}$ after surgery significantly decreased in $\mathrm{SH}$ group $(\mathrm{P}<0.05)$. Compared with $\mathrm{SH}$ group, the periumbilical mechanical thresholds $6 \mathrm{~h}$ and $24 \mathrm{~h}$ after surgery were significantly higher in PH group $(\mathrm{P}<0.05)$. However, $\mathrm{PH}$ and $\mathrm{SL}$ groups had similar results $(\mathrm{P}>0.05)$ (Fig. 1).
$V A S$ scores at different time points

Compared with SL group, VAS scores significantly increased $30 \mathrm{~min}, 2 \mathrm{~h}$ and $6 \mathrm{~h}$ after surgery in $\mathrm{SH}$ group $(\mathrm{P}<0.05)$. Compared with $\mathrm{SH}$ group, VAS scores $30 \mathrm{~min}, 2 \mathrm{~h}$ and $6 \mathrm{~h}$ after surgery were significantly lower in $\mathrm{PH}$ group $(\mathrm{P}<0.05)$. Nevertheless, $\mathrm{PH}$ and SL groups had similar results $(\mathrm{P}>0.05)$ (Fig. 2).

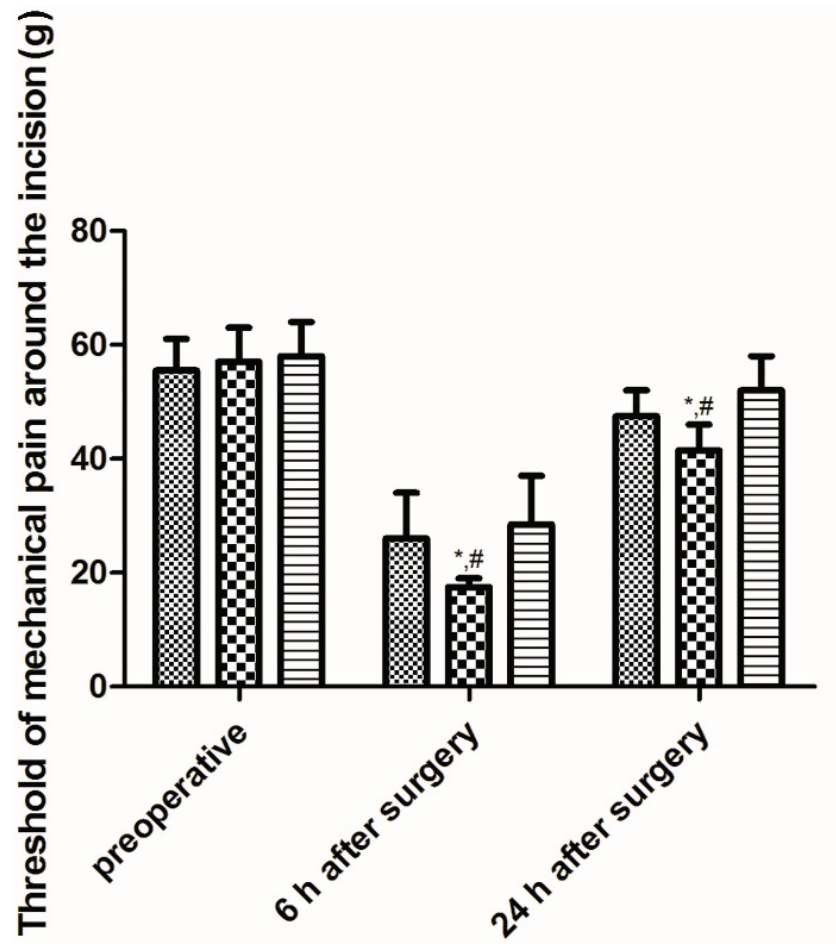

Fig. 1. Postoperative periumbilical mechanical pain thresholds $(n=60$, $\mathrm{X} \pm \mathrm{SD}$ ). ${ }^{*}$ Compared with SL group, $\mathrm{P}<0.05$; \# compared with $\mathrm{PH}$ group, $\mathrm{P}<0.05$. $\mathrm{PH}:$ Propofol + high-dose remifentanil; SL: sevoflurane + lowdose remifentanil.

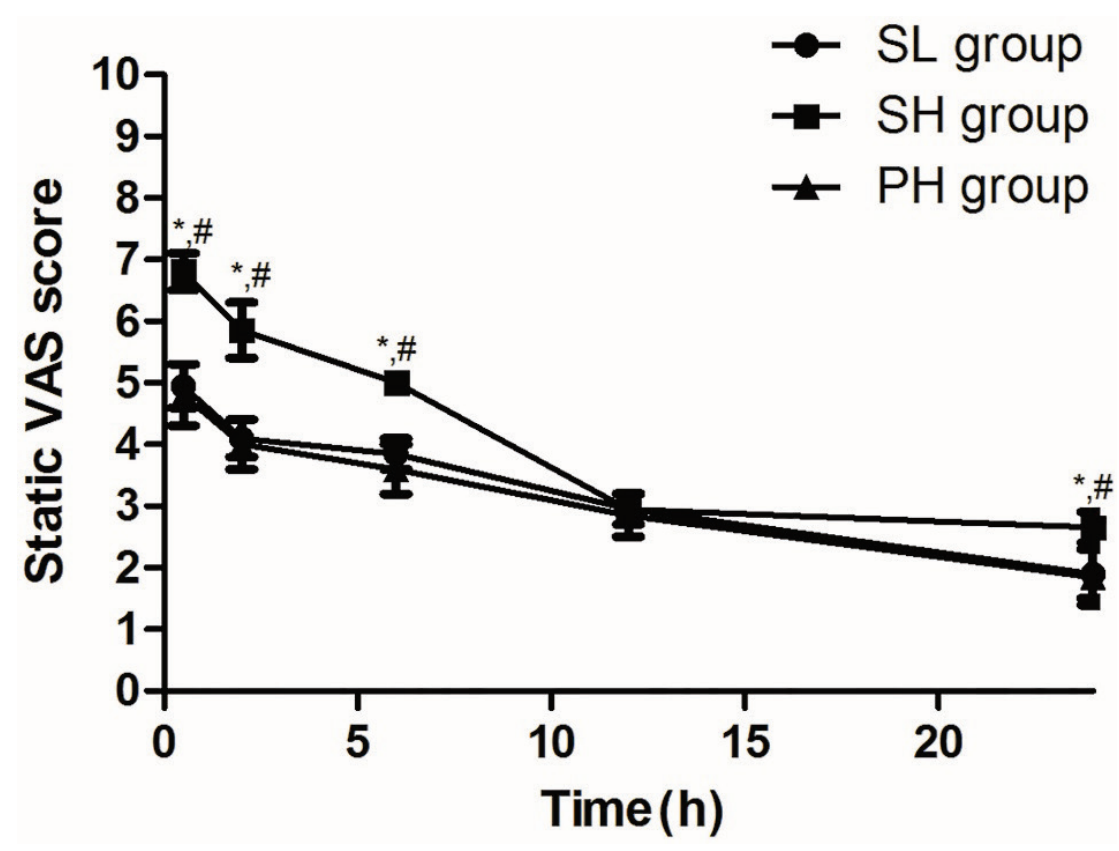

Fig. 2. VAS scores at different time points $(n=60, X \pm S D) .{ }^{*}$ Compared with SL group, $\mathrm{P}<0.05$; \# compared with $\mathrm{PH}$ group, $\mathrm{P}<0.05$. $\mathrm{PH}$ : Propofol + high-dose remifentanil; SL: sevoflurane + low-dose remifentanil. 
Correlation between periumbilical mechanical pain threshold and VAS score

The periumbilical mechanical pain thresholds and VAS scores $6 \mathrm{~h}$ and $24 \mathrm{~h}$ after surgery were not significantly correlated $(\mathrm{P}>0.05)$ (Table 2$)$.

Time of first using PCIA pump and total sufentanil consumption after surgery

PH group $18.7 \pm 4.7 / \mathrm{min}$ and SL group $17.8 \pm 5.0 / \mathrm{min}$ used PCIA pump for the first time significantly later than $\mathrm{SH}$ group did $11.3 \pm 3.6 / \mathrm{min}$ $(\mathrm{P}<0.05)$. The total consumptions of sufentanil in $\mathrm{PH}$ and SL groups were significantly lower than that of SH group $(\mathrm{P}<0.05)$ (Fig. 3).

Incidence rates of related adverse reactions

The incidence rates of bradycardia and postoperative chill in $\mathrm{PH}$ and $\mathrm{SH}$ groups were significantly higher than those of SL group $(\mathrm{P}<0.05)$ (Table 3).

Table 2. Correlation between periumbilical mechanical pain threshold and VAS score.

VAS score

Postoperative $6 \mathrm{~h}$

Postoperative $24 \mathrm{~h}$
Periumbilical mechanical pain threshold

\section{Postoperative $6 \mathrm{~h}$}

$\mathrm{r}=-0.236, \mathrm{P}=0.698$
Postoperative $24 \mathrm{~h}$

$\mathrm{r}=0.203, \mathrm{P}=0.081$

VAS: Visual analog scale.

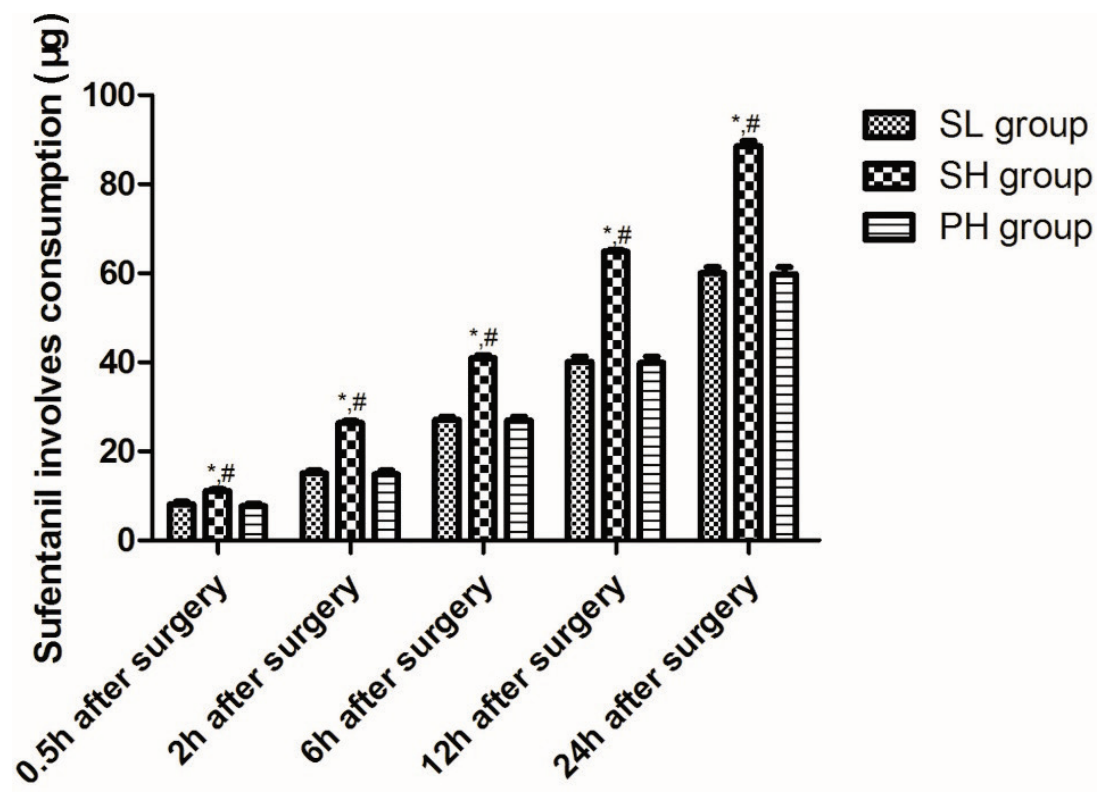

Fig. 3. Total sufentanil consumption after surgery $(n=60, X \pm S D)$. ${ }^{*}$ Compared with SL group, $\mathrm{P}<0.05$; * compared with $\mathrm{PH}$ group, $\mathrm{P}<0.05$. $\mathrm{PH}$ : Propofol + high-dose remifentanil; SL: sevoflurane + low-dose remifentanil.

Table 3. Incidence rates of related adverse reactions $(\%, n=60)$.

\begin{tabular}{lcccc}
\hline Group & Hypotension & Bradycardia & Postoperative chill & Nausea and vomiting \\
\hline$S L$ & $12(20.00)$ & $8(13.00)$ & $10(17.00)$ & $20(33.00)$ \\
$S H$ & $22(37.00)$ & $14(47.00)$ & $32(53.00)$ & $26(43.00)$ \\
$P H$ & $20(33.00)$ & $26(43.00)$ & $30(50.00)$ & $16(27.00)$ \\
$\chi^{2}$ & 4.444 & 14.318 & 20.556 & 3.740 \\
$P$ & 0.108 & $<0.001$ & $<0.001$ & 0.154 \\
\hline
\end{tabular}

PH: Propofol + high-dose remifentanil group; SH: sevoflurane + high-dose remifentanil; SL: sevoflurane + low-dose remifentanil. 


\section{Discussion}

In this study, compared with the SL group, the mechanical threshold for postoperative surgical incision, 24-h sufentanil consumption and VAS scores $30 \mathrm{~min}, 2 \mathrm{~h}$, $6 \mathrm{~h}$ and $24 \mathrm{~h}$ after surgery of the SH group significantly reduced, indicating that high-dose remifentanil induced postoperative hyperalgesia. In addition, compared with the $\mathrm{SH}$ group, the $\mathrm{PH}$ group had higher mechanical pain threshold after surgery as well as lower cumulative consumption and VAS score, suggesting that propofol combined with high-dose remifentanil alleviated postoperative hyperalgesia induced by remifentanil.

Short-acting opioid remifentanil is more susceptible to acute tolerance and/or hyperalgesia, leading to increased postoperative pain, morphine use and pain sensitivity. Wang et al. (2009) reported that $0.3 \mu \mathrm{g} / \mathrm{kg} / \mathrm{min}$ remifentanil reduced the mechanical pressure pain threshold of patients, and led to hyperalgesia. Sustained long-term intravenous infusion with remifentanil can result in postoperative acute tolerance and hyperalgesia, although animal studies revealed that acute tolerance usually occurred after 2-3 h of constant-rate infusion and hyperalgesia usually took place within $1 \mathrm{~h}$ after infusion (Ishida et al. 2012). However, it is difficult to distinguish between the two phenomena in clinical practice. Acute tolerance to opioids is considered potential hyperalgesia. They can co-exist and share many common pathways. Acute tolerance can be ascribed to the desensitization of opioids via the pain signaling pathway, which is equivalent to the loss of some pharmacological effects. OIH is sensitized by opioid-mediated pain signaling pathways (Gold MS 2015). These pathways lead to an increase in noxious load and require a more aggressive dose of opioid to achieve adequate analgesia.

In this study, compared with the SL group, the SH group had increased demand for sufentanil and higher VAS score in the early postoperative period (within $30 \mathrm{~min}$ after surgery), probably being associated with acute tolerance. Patients who underwent laparoscopic cholecystectomy had no significant difference in the degree of surgical trauma. Thus, the differences between pain sensitivity and pain threshold were observed early in the postoperative period, due to different doses of fentanyl. Previous studies on hyperalgesia mostly used patient's pain sensation or postoperative analgesic consumption to indirectly indicate the occurrence and extent of hyperalgesia. The results were often subjective and inaccurate, because there was no pain hyperalgesia or private pain complaint after surgery (Richebé et al. 2011). Accordingly, the postoperative pain score does not accurately reflect the hyperalgesia of postoperative incision. In view of this, Tena et al. (2012) first used Von Frey monofilaments (VFM) equipment to determine the mechanical pain threshold and the secondary hyperalgesia in the area around surgical incision, making the judgment of hyperalgesia more objective. The EVF device used in this study was a standard quantitative new method for detecting the mechanical pain threshold of human body. Compared with the traditional VFM pain tester, the operation process is faster, and the results are more accurate and reliable.

At present, the mechanisms by which remifentanil causes hyperalgesia focus on the NMDA receptor pathway. Glutamate is an excitatory neurotransmitter in the central nervous system. It activates glutamate receptors and participates in the transmission of nociceptive information and the triggering mechanism of hyperalgesia. NMDA receptors play an important role in the mechanism of OIH (Kaye et al. 2014). After the NMDA receptor pathway is activated, a large amount of NO is promoted by NOS, thereby increasing the excitability of neurons, sensitizing the pain center, enhancing noxious stimulation signals and inducing hyperalgesia. Some basic studies have shown that propofol inhibited NMDA glutamate subtype receptors (de la Peña et al. 2014), while reduced hyperalgesia by regulating NMDA receptor-mediated increase of intracellular calcium (Chen et al. 2017). Bandschapp et al. (2010) concluded that propofol had analgesic and antiallergic effects. Related clinical studies have verified that propofol delayed and mitigated remifentanil-induced hyperalgesia (Rivosecchi et al. 2014). Shin et al. (2010) found that remifentanil-induced hyperalgesia was not evident using propofol compared with that using sevoflurane, although the target concentration of remifentanil reached $4.0 \mathrm{ng} / \mathrm{ml}$. Therefore, propofol exerted regulatory effects on $\mathrm{OIH}$, similar to the results of this study. A meta-analysis showed that anesthesia using propofol was able to prevent the development of hypersensitivity caused by remifentanil (Fletcher and Martinez 2014). In perioperative treatment to reduce $\mathrm{OIH}$, propofol may have preventive effects (Potter and Moon 2015). However, sevoflurane also involved antiNMDA receptors in a dose-dependent manner (Lapébie et al. 2014). At clinically applied concentrations, the effect of sevoflurane on hyperalgesia is insufficient to 
prevent that of high-dose remifentanil, and hyperesthesia can be induced by noxious stimulation (Richebé et al. 2009). Moreover, propofol easily crosses the blood-brain barrier and is evenly distributed in the brain and spinal cord, acting on the GABAA receptor in the spinal cord, and reacts with GABA and type A receptors (Maldifassi et al. 2016). GABA receptor is a key inhibitory neurotransmitter for central pain regulation. Animal experiments have shown that fentanyl can be observed in the hippocampal CA1 region of rats and the sensitivity of vertebral neurons to presynaptic stimulation is increased. The decrease in GABA in neuronal cell bodies and processes indicates a reduction in GABA released into vertebral neurons during hyperalgesia (McCarson and Enna 2014). Propofol may also modulate OIH by enhancing the interaction of GABA with type A receptors and interacting with NMDA receptors at the level of the spinal cord.

We herein demonstrated that propofol may reduce postoperative hyperalgesia induced by high-dose remifentanil through more potent NMDA receptor antagonism compared with anesthesia using high-dose remifentanil-sevoflurane. Compared with sevoflurane inhalation anesthesia, propofol anesthesia was more conducive to postoperative recovery, including reduction of sufentanil consumption and alleviation of postoperative pain. Although propofol can overcome nausea and vomiting during surgery, we observed no significant difference between the incidence rates of these symptoms, probably because patients were prevented from using antiemetics. Furthermore, the incidence rate of postoperative chill was significantly higher in the high-dose remifentanil group, whether in combination with propofol or sevoflurane for anesthesia, indicating that propofol did not work for postoperative chill.

In summary, anesthesia by using high-dose remifentanil $(0.3 \mu \mathrm{g} / \mathrm{kg} / \mathrm{min})$ infusion with sevoflurane induced postoperative hyperalgesia, which was mitigated by intravenous administration with propofol-remifentanil. Therefore, intravenous anesthesia with propofolremifentanil was superior to inhalation anesthesia with sevoflurane-remifentanil in suppressing hyperalgesia induced by high-dose remifentanil.

\section{Conflict of Interest}

There is no conflict of interest.

\section{Acknowledgements}

This study was not financially supported.

\section{References}

AHMED SS, NITU M, HICKS S, HEDLUND L, SLAVEN JE, RIGBY MR: Propofol-based procedural sedation with or without low-dose ketamine in children. J Pediatr Intensive Care 5: 1-6, 2016. https://doi.org/10.1055/s0035-1568152

BANDSCHAPP O, FILITZ J, IHMSEN H, BERSET A, URWYLER A, KOPPERT W, RUPPEN W: Analgesic and antihyperalgesic properties of propofol in a human pain model. Anesthesiology 113: 421-428, 2010. https://doi.org/10.1097/ALN.0b013e3181e33ac8

BEKHIT MH: Opioid-induced hyperalgesia and tolerance. Am J Ther 17: 498-510, 2010. https://doi.org/10.1097/MJT.0b013e3181ed83a0

CHEN X, WU Q, YOU L, CHEN S, ZHU M, MIAO C: Propofol attenuates pancreatic cancer malignant potential via inhibition of NMDA receptor. Eur J Pharmacol 795: 150-159, 2017. https://doi.org/10.1016/j.ejphar.2016.12.017

DE LA PEÑA JB, AHSAN HM, DELA PEÑA IJ, PARK HB, KIM HJ, SOHN A, KIM YT, CHEONG JH: Propofol pretreatment induced place preference and self-administration of the tiletamine-zolazepam combination: implication on drug of abuse substitution. Am J Drug Alcohol Abuse 40: 321-326, 2014. https://doi.org/10.3109/00952990.2014.920850

FLETCHER D, MARTINEZ V: Opioid-induced hyperalgesia in patients after surgery: a systematic review and a metaanalysis. Br J Anaesth 112: 991-1004, 2014. https://doi.org/10.1093/bja/aeu137

GOLD MS, BACKONJA MM: Pain: from neurobiology to disease. In: Neurobiology of Brain Disorders. ZIGMOND MJ, ROWLAND LP, COYLE JT (eds), Academic Press, 2015, pp 674-692. https://doi.org/10.1016/B978-0$\underline{12-398270-4.00041-0}$ 
ISHIDA R, NIKAI T, HASHIMOTO T, TSUMORI T, SAITO Y: Intravenous infusion of remifentanil induces transient withdrawal hyperalgesia depending on administration duration in rats. Anesth Analg 114: 224-229, 2012. https://doi.org/10.1213/ANE.0b013e318237f678

KAYE AD, CHUNG KS, VADIVELU N, CANTEMIR C, URMAN RD, MANCHIKANTI L: Opioid induced hyperalgesia altered with propofol infusion. Pain Physician 17: E225-E228, 2014.

LAPÉBIE FX, KENNEL C, MAGY L, PROJETTI F, HONNORAT J, PICHON N, VIGNON P, FRANÇOIS B: Potential side effect of propofol and sevoflurane for anesthesia of anti-NMDA-R encephalitis. BMC Anesthesiol 14: 5, 2014. https://doi.org/10.1186/1471-2253-14-5

LEE M, SILVERMAN SM, HANSEN H, PATEL VB, MANCHIKANTI L: A comprehensive review of opioidinduced hyperalgesia. Pain Physician 14: 145-161, 2011.

MALDIFASSI MC, BAUR R, SIGEL E: Functional sites involved in modulation of the GABAA receptor channel by the intravenous anesthetics propofol, etomidate and pentobarbital. Neuropharmacology 105: 207-214, 2016. https://doi.org/10.1016/j.neuropharm.2016.01.003

MCCARSON KE, ENNA SJ: GABA pharmacology: the search for analgesics. Neurochem Res 39: 1948-1963, 2014. https://doi.org/10.1007/s11064-014-1254-X

POTTER JV, MOON RE: Why do some patients stop breathing after taking narcotics? Ventilatory chemosensitivity as a predictor of opioid-induced respiratory depression. J Appl Physiol 119: 420-422, 2015. https://doi.org/10.1152/japplphysiol.00034.2015

RICHEBÉ P, RIVALAN B, RIVAT C, LAULIN JP, JANVIER G, MAURETTE P, SIMONNET G: Effects of sevoflurane on carrageenan-and fentanyl-induced pain hypersensitivity in Sprague-Dawley rats. Can J Anesth 56: 126-135, 2009. https://doi.org/10.1007/s12630-008-9023-4

RICHEBÉ P, POUQUET O, JELACIC S, MEHTA S, CALDERON J, PICARD W, RIVAT C, CAHANA A, JANVIER G: Target-controlled dosing of remifentanil during cardiac surgery reduces postoperative hyperalgesia. J Cardiothorac Vasc Anesth 25: 917-925, 2011. https://doi.org/10.1053/j.jvca.2011.03.185

RIVOSECCHI RM1, RICE MJ, SMITHBURGER PL, BUCKLEY MS, COONS JC, KANE-GILL SL: An evidence based systematic review of remifentanil associated opioid-induced hyperalgesia. Expert Opin Drug Saf 13: 587-603, 2014. https://doi.org/10.1517/14740338.2014.902931

SHIN SW, CHO AR, LEE HJ, KIM HJ, BYEON GJ, YOON JW, KIM KH, KWON JY: Maintenance anaesthetics during remifentanil-based anaesthesia might affect postoperative pain control after breast cancer surgery. Br $\mathrm{J}$ Anaesth 105: 661-667, 2010. https://doi.org/10.1093/bja/aeq257

TENA B, ESCOBAR B, ARGUIS MJ, CANTERO C, RIOS J, GOMAR C: Reproducibility of electronic von Frey and von Frey monofilaments testing. Clin J Pain 28: 318-323, 2012. https://doi.org/10.1097/AJP.0b013e31822f0092

WANG FJ, WAN Y, LIU Y: The dose-dependent relationship of remifentanil inducing postoperative hyperalgesia. (In Chinese) J Clin Anesthesiol 25: 937-939, 2009.

YU EH, TRAN DH, LAM SW, IRWIN MG: Remifentanil tolerance and hyperalgesia: short-term gain, long-term pain? Anaesthesia 71: 1347-1362, 2016. https://doi.org/10.1111/anae.13602 